\title{
PENGARUH PERSEPSI HARGA DAN CITRA MEREK TERHADAP LOYALITAS PELANGGAN MENGGUNAKAN PRODUK KOSMETIK (Studi Pada Swalayan Grand Hero di Kota Palu)
}

\author{
RABIATUL ADAWIAH \\ SYAMSUL BAHRI DG. PARANI \\ FARID \\ Jurusan Manajemen, Fakultas Ekonomi, Universitas Tadulako \\ Email: bia.rabiatul@yahoo.com
}

\begin{abstract}
The purpose of this study is to determine the influence of price and brand image both simultaneously and partially to customer loyalty at grand hero Supermarkets in the city of Palu. The independent variables used in this study are price and brand image. While the dependent variable is Customer Loyalty $(Y)$. The research method used in this research is descriptive causal method. The sample used in this study were as many as 93 respondents with the form of sampling using accidental sampling and Purposive Sampling techniques. Data analysis method used in this research is multiple linear regression analysis method. The results of this study indicate that simultaneously the price and brand image have a significant effect on customer loyalty at grand hero supermarket in the city of hammer. Partially significant effect on customer loyalty using viva cosmetic product at grand hero supermarket in Palu City.
\end{abstract}

Keywords: Price, Brand image, Customer loyalty

\section{ABSTRAK}

Tujuan dari penelitian ini yaitu untuk mengetahui pengaruh harga dan citra merek baik secara serempak maupun parsial terhadap loyalitas pelanggan pada Swalayan grand hero di Kota Palu. Variabel independen yang digunakan dalam penelitian ini adalah harga dan citra merek. Sedangkan variable dependen adalah Loyalitas pelanggan (Y). Metode penelitian yang digunakan dalam penelitian ini adalah metode deskriptif kausal. Sampel yang digunakan pada penelitian ini yaitu sebanyak 93 responden dengan bentuk pengambilan sampel menggunakan teknik accidental Sampling dan Purposive Sampling. Metode analisis data yang digunakan dalam penelitian ini adalah metode analisis regresi linear berganda. Hasil penelitian ini menunjukkan bahwa secara simultan harga dan citra merek berpengaruh signifikan terhadap loyalitas pelanggan pada swalayan grand hero di kota palu. Secara parsial berpengaruh signifikanterhadap loyalitas pelanggan menggunakan produk kosmetik viva pada swalayan grand hero di Kota Palu.

Kata Kunci: Harga, Citra merek, Loyalitas pelanggan.

\section{PENDAHULUAN}

Di Sulawesi Tengah khususnya Kota Palu terdapat beberapa ritel yang menjual kosmetik dengan berbagai macam merek, baik produk dalam negeri maupun produk luar negeri. Hadirnya beberapa ritel kosmetik di Kota Palu menyebabkan terjadinya persaingan yang semakin kuat. Hal ini menuntut para pelaku bisnis ritel kosmetik tersebut untuk menyusun strategi yang tepat untuk merebut perhatian pelanggan.

Salah satu ritel yang menjual kosmetik di Kota Palu yaitu pada swalayan grand hero yang terletak di jalan basuki rahmat No. 31 Palu. Grand hero adalah salah satu swalayan yang menjual produk kosmetik dan produk merek lainnya yang banyak menjadi pilihan utama masyarakat Kota Palu, hal ini dapat dilihat dari tingkat kunjungan yang cukup tinggi berdasarkan keramaian pengunjung pada swalayan grand hero setiap harinya.

Salah satu produk yang suda terkenal di mata konsumen yaitu produk kosmetik viva, namun produk kosmetik viva adalah produk yang memiliki image sebagai kosmetik kecantikan bagi kaum 
wanita, selain itu terdapat banyak kosmetik lain yang bermunculan saat ini, hal ini tentunya akan menjadi salah satu pertimbangan konsumen untuk membeli produk kosmetik viva pada swalayan grand hero.

Selain citra merek yang mendukung tercapainya loyalitas pelanggan terdapat beberapa keuntungan strategik bagi perusahaan tentang pentingnya mempertahankan loyalitas pelanggan. Imbalan dari loyalitas bersifat jangka panjang dan kumulatif. Jadi, semakin lamanya loyalitas seorang pelanggan, akan semakin besar laba yang dapat diperoleh perusahaan dari seorang pelanggan. Pelanggan yang loyal akan menjadi yang sangat bernilai bagi suatu perusahaan atau oragnisasi. Kotler \& Keller (2009: 155) berpendapat bahwa pelanggan yang puas dan loyal (setia) merupakan peluang untuk mendapatkan pelanggan baru. Mempertahankan semua pelanggan yang ada umumnya, akan lebih menguntungkan dibandingkan dengan pergantian pelanggan karena biaya untuk menarik pelanggan baru bisa lima kali lipat dari biaya mempertahankan seorang pelanggan yang sudah ada.

Tujuan penelitian ini adalah untuk menganalisa pengaruh harga dan citra merek terhadap loyalitas pelanggan yang menggunakan produk kosmetik viva pada swalayan grand hero di kota Palu, untuk mengetahui pengaruh harga terhadap loyalitas pelanggan yang menggunakan produk kosmetik viva pada swalayan grand hero di kota Palu, dan untuk mengetahui pengaruh citra merek terhadap loyalitas pelanggan yang menggunakan produk kosmetik viva pada swalayan grand hero di kota Palu.

\section{KAJIAN LITERATURE \\ Pengertian Produk}

Menurut Kotler dan Armstrong (2009:4) banyak orang menganggap produk suatu penawaran nyata, tetapi produk bisa lebih dri itu. Secara luas, Produk (product) adalah segala sesuatu yang dapat ditawarkan kepada pasar untuk memuaskan suatu keinginan atau kebutuhan, termasuk barang fisik, jasa, pengalaman, acara, orang, tempat, properti, organisasi, informasi, dan ide.

\section{Harga}

Harga adalah jumlah uang dibebankan untuk barang/jasa. Harga juga dapat dikatakan sebagai jumlah nilai yang konsumen tukarkan untuk manfaat memiliki atau menggunakan barang/jasa. Vinci (2009:129). Bagi konsumen harga merupakan salah satu faktor yang mempengaruhi pemilihan pembelian. Bagi usaha pengecer, harga salah satu elemen ritel yang menghasilkan pendapatan dan mewakili besarnya biaya. Selain itu, harga salah satu elemen yang fleksibel, karena dapat diubah dengan cepat.

Menurut Kotler dan Amstrong (2008:27) harga merupakan faktor utama penentuan posisi dan harus diputuskan sesuai dengan pasar sasaran, produk dan pelayanan,serta persaingan. Strategi kebijakan penetapan harga merupakan suatu masalah jika perusahaan akan menetapkan harga pertama kalinya, karena penetapan harga akan mempengaruhi pendapatan total dan biaya. Harga merupakan faktor utama penentuan posisi dan harus diputuskan sesuai dangan pasar sasaran, bauran ragam produk, dan pelayanan serta persaingan Foster (2008 :57). Strategi penentuan harga sangat signifikan dalam pemberian nilai kepada konsumen dan mempengaruhi citra produk, serta keputusan konsumen membeli. Penentuan harga juga berhubungan dengan pendapatan dan turut mempengaruhi penawaran atau saluran pemasaran.

\section{Citra Merek}

Menurut Aanker dalam Sangadji \& Shopiah (2013) Citra Merek adalah seperangkat asosiasi unik yang ingin diciptakan atau dipelihara oleh pemasar. Asosiasi-asosiasi itu menyatakan apa sesungguhnya merek dan apa yang dijanjikan kepada konsumen." Menurut UU Merek N0.15 Tahun 2001 pasal 1 ayat 1 dalam (Tjiptono \& Chandra, 2012) Merek adalah tanda yang berupa gambar, nama, kata, huruf-huruf, angka-angka susunan wana, atau kombinasi dari unsur-unsur tersebut yang memiliki daya pembeda dan digunakan dalam kegiatan perdagangan barang atau jasa. Perkembangan terakhir menunjukan bahwa bentuk, suara, hologram, dan bahkan aroma juga dimasukan dalam 
lingkup definisi merek (Tjiptono, 2012), Melalui pengetahuan merek yang cukup, konsumen dapat menghemat waktu dan biaya pencarian (searching cost) serta menghindari risiko-risiko yang dapat muncul kemudian, seperti risiko fungsional, finansial, fisik, sosial, dan psikologis. Bagi konsumen, kesan merek yang melekat pada suatu produk disebut citra merek. Fenomena persaingan yang ada dalam era globalisasi akan semakin mengarahkan sistem perekonomian Indonesia ke mekanisme pasar yang memposisikan pemasar untuk selalu mengembangkan dan merebut market share (pangsa pasar). Salah satu aset untuk mencapai keadaan tersebut adalah brand (merek).

Sulistian (2011: 32) mendefinisikan citra merek sebagai seperangkat keyakinan, ide, dan kesan yang di miliki oleh seseorang terhadap suatu merek, karena itu sikap dan tindakan konsumen terhadap suatu merek sangat ditentukan oleh citra merek tersebut. Citra merek merupakan syarat dari merek yang kuat. Simamora dalam (Sulistian, 2011: 33), mengatakan citra adalah persepsi yang relatif konsisten dalam jangka waktu panjang, sehingga tidak mudah untuk membentuk citra, citra sekali terbentuk akan sulit untuk mengubahnya. Citra yang dibentuk harus jelas dan memiliki keunggulan bila dibandingkan dengan pesaingnya, saat perbedaan dan keunggulan merek dihadapkan dengan merek lain. Komponen citra merek (brand image) terdiri atas tiga bagian, yaitu:

1) Citra pembuat (corporate image), yaitu sekumpulan asosiasi yang dipersepsikan konsumen terhadap perusahaan yang membuat suatu barang atau jasa.

2) Citra pemakai (user image), yaitu sekumpulan asosiasi yang dipersepsikan konsumen terhadap pemakai yang menggunakan suatu barang atau jasa.

3) Citra produk (product image), yaitu sekumpulan asosiasi yang dipersepsikan konsumen terhadap suatu barang atau jasa.

\section{Faktor-Faktor Pembentuk Citra Merek}

Sehhiffman dan Kanuk (2011:135) menyebut faktor-faktor pembentuk citra merek sebagai berikut:

1. Kualitas atau mutu berkaitan dengan kualitas produk barang atau jasa yang ditawarkan oleh produsen dengan merek tertentu.

2. Dapat dipercaya atau diandalkan,berkaitan dengan pendapat atau kesepakatan yang dibentuk oleh masyarakat tentang suatu produk yang dikonsumsi.

3. Kegunaan atau manfaat, yang terkait dengan fungsi dari suatu produk barang atau jasa yang bias dimanfaatkan untutk konsumen.

4. Pelayanan,yang berkaitan dengan tugas produsen dalam melayani.

5. Resiko, berkaitan dengan besar-kecilnya akibat atau untung rugi yang mungkin dialami oleh konsumen.

6. Harga, yang dalam hal ini berkaitan dengan tinggi-rendahnya atau banyak-sedikitnya jumlah uang yang dikeluarkan konsumen mempengaruhi suatu produk,jugaa dapat mempengaruhi citra jangka panjang.

7. Citra yang dimiliki oleh merek itu sendiri, yaitu berupa pandangan,kesepakatan, dan informasi yang berkaitan dengan suatu merek dari produk tertentu.

\section{Loyalitas Pelanggan}

Pelanggan adalah seseorang yang menjadi terbiasa untuk membeli dari suatu perusahaan. Kebiasaan itu terbentuk melalui pembelian dan interaksi yang sering selama periode waktu tertentu. Tanpa adanya track record hubungan yang kuat dan pembelian berulang, orang tersebut bukanlah pelanggan, ia adalah pembeli. Pelanggan sejati tumbuh seiring waktu, Griffin (2005;31).

Definisi loyalitas konsumen foster (2008: 174) yaitu: suatu komitmen yang mendalam untuk melakukan pembelian atau berlangganan atas suatu produk atau pelayanan secara konsisten untuk masa datang, serta tidak terpengaruh pada lingkungan yang ada atau upaya-upaya yang ada atau upaya-upya yang dilakukan,serta hal-hal yang berpotensi pada kemungkinan berpindahnya si pelanggan keperusahaan pesaing. 
Tjiptono (2014: 393) juga mengemukakan bahwa loyalitas pelanggan adalah komitmen pelanggan terhadap suatu merek,toko,atau pemasok, berdasarkan sikap yang sangat positif dan tercermin dalam pembelian ulang yang konsisten"'. Loyalitas adalah situasi dimana konsumen bersikap positif terhadap produk atau produsen (penyedia jasa) yang diliputi dangan pola pembelian ulang yang konsisten.

\section{Tahap-Tahap Pertumbuhan Loyalitas Pelanggan}

Griffin (2005:35) ada tujuh tahap pertumbuhan seseorang menjadi pelanggan yang loyal, yaitu:

1. Sesorang yang mempunyai kemungkinan pembeli (suspect), Setiap orang mempunyai kemungkinan untuk membeli produk atau jasa yang dihasilkan.

2. Sesorang mempunyai potensi untuk menjadi pelanggan (prospect), Sesorang yang telah mempunyai kebutuhan akan barang dan mempunyai kebutuhan untuk membeli dari perusahaan dan telah ada sesorang yang merekomendasikan tentang perusahaan. Prospect mungkin tahu tentang perusahaan, dan apa yang perusahaan jual tapi masih belum membeli dari perusahaan.

3. Seseorang yang tidak jadi menjadi pelanggan (Disqualifed), Prospect yang telah cukup perusahaan pelajari dan mereka tidak membutuhkan atau tidak mempunyai kemampuan untuk membeli produk perusahaan.

4. Pelanggan baru (first time customer), Mereka yang baru pertama kali membeli dari perusahaan. Mereka mungkin pelanggan perusahaan tapi masih menjadi pelanggan pesaing perusahaan.

5. Pelanggan yang melakukan pembelian berulang (repeat customer), Mereka yang pertamakali memberi dari perusahaan dua kali atau lebih, mereka mungkin telah membeli produk yang sama atau membelih dua produk yang berbeda dalam dua kali atau dua kesempatan.

6. Mitra (Client), Seseorang klien membeli semua yang perusahaan jual mungkin dapat ia gunakan. Orang ini memberi secara regular. Perusahaan harus terus berusaha menciptakan hubungan yang akan membuat dia tidak tertarik pada pesaing.

7. Pelanggan yang memajukan (Advocate), Advocate semua seperti mitra, tambahannya, seorang advocate berbiacara dengan perusahaan, melakukan pemasaran untuk perusahaan dan membawa pelanggan kepada perusahaan.

\section{Indikator Loyalitas Pelanggan}

Indikator loyalitas pelanggan menurut Griffin (2005:31) adalah:

1. Pembelian ulang secara teratur, konsumen yang memiliki loyalitas yang tinggi pada suatu produk akan melakukan proses pembelian produk secara tingkat berkesinambungan dan tingkat skala pembeliannya mungkin akan meningkat.

2. Menunjukan kekebalan terhadap tarikan pesaing, setiap perusahaan akan berusaha dengan baebagai cara untuk menarik pelanggan yang dimiliki oleh pesaing, bagi pelanggan yang memiliki loyalitas terhadap produk yang di produksi oleh perusahaan tertentu ia tidak akan mudah untuk beralih kemerek lain meskipun terus menerus digempur dengan penawaran yang ditawarkan oleh perusahaan lainya.

3. Mereferensikan kepada orang lain, loyalitas pelanggan terhadap produk muncul melalui beberapa proses yang dijalaninya, salah satunya proses penggunaan produk secara terus menerus dikarenakan konsumen merasa bahwa kepuasanya terpenuhi dengan baik. 


\section{Kerangka Pemikiran}

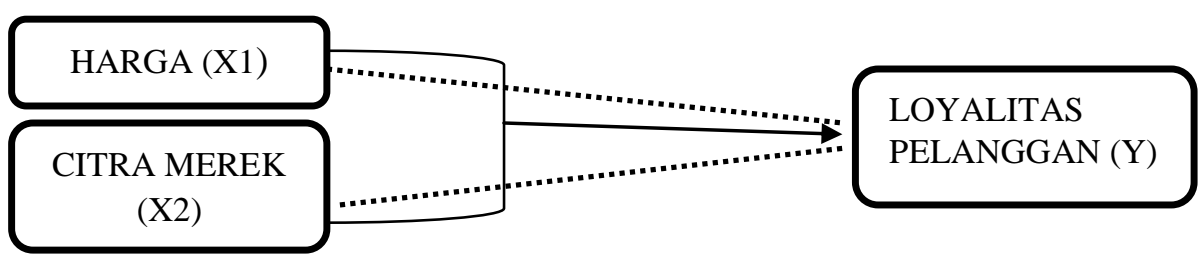

Gambar 1

\section{Kerangka Pemikiran}

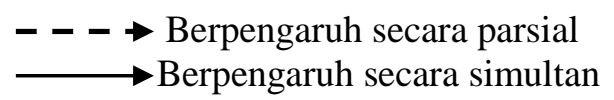

\section{Hipotesis}

1. Harga dan citra merek secara serempak berpengaruh signifikan terhadap loyalitas pelanggan produk kosmetik Viva Pada swalayan grand hero di Kota Palu.

2. Harga berpengaruh signifikan terhadap loyalitas pelanggan produk kosmetik Viva Pada swalayan grand hero di Kota Palu.

3. Citra merek berpengaruh signifikan terhadap loyalitas pelanggan produk kosmetik Viva Pada swalayan grand hero di Kota Palu.

\section{METODE PENELITIAN}

Jenis penelitian yang akan digunakan adalah deskriptif kausal. Menurut Sugiyono (2013:22) "Penelitian deskriptif adalah metode yang digunakan untuk menganalisa data dengan cara mendeskripsikan atau menggambarkan data yang telah terkumpul sebagaimana adanya tanpa bermaksud membuat kesimpulan yang berlaku untuk umum atau generalisasi”. Menurut Sugiyono (2013: 56), desain kausal adalah hubungan yang bersifat sebab akibat. Jadi, variabel independen (mempengaruhi) dan variabel dependen (dipengaruhi). Di mana penelitian kausal yaitu penelitian untuk menguji hubungan antara variabel yang dihipotesiskan.

Populasi dalam penelitian ini adalah pelanggan yang menggunakan produk kosmetik viva di kota palu. Penelitian ini, jumlah populasi tidak diketahui secara pasti karena tidak adanya data pendukung yang menunjukkan data pelanggan yang membeli produk kosmetik viva ini. Demikian populasi dalam penelitian ini dikategorikan non probability sampling.

Teknik yang digunakan dalam pengambilan sampel accidental sampling dan Purposive Sampling adalah cara pengambilan sampel berdasarkan sampel berdasarkan karakteristik tertentu. Dikarenakan jumlah populasinya tidak diketahui secara pasti maka untuk menentukan besarnya sampel yaitu dengan menggunakan rumus Unknown Populations Frendy dalam Ekasari (2014: 98)

$$
\mathrm{n}=\frac{\mathrm{Z}^{2}}{4 \mu^{2}}
$$

\section{Keterangan:}

$\mathrm{n}=$ ukuran sampel

$\mathrm{Z}=$ tingkat keyakinan sampel yang dibutuhkan dalam penelitian, pada $\alpha=5 \%$ (derajat keyakinan ditentukan 95\%) maka $\mathrm{Z}=1,96$

$\mu=$ margin of error, tingkat kesalahan yang dapat ditolerir (ditentukan 10\%)

Dengan menggunakan rumus diatas, maka diperoleh perhitungan sebagai berikut:

$$
\begin{aligned}
& \mathrm{n}=\frac{1,96^{2}}{4(0,1)^{2}} \\
& \mathrm{n}=96,4 \approx 97 \text { responden }
\end{aligned}
$$




\section{Analisis Regresi Berganda}

Sugiyono (2014:277) bahwa model umum bentuk persamaan alat analisis statistic parametric regresi linear berganda dapat digambarkan sebagai berikut persamaan struktural dalam model sebagai berikut:

$\mathbf{Y}=\mathbf{a}+\mathbf{b}_{1} \mathbf{X}_{1}+\mathbf{b}_{2} \mathbf{X}_{2}+\ldots+\mathbf{e}$

Keterangan:

$\begin{array}{ll}\mathrm{Y} & \text { : Loyalitas Konsumen } \\ \alpha & \text { : Konstanta } \\ \mathrm{b}_{1}-\mathrm{b}_{5} & \text { : Koefisien Regresi } \\ \mathrm{X} 1 & \text { : Harga } \\ \mathrm{X} 2 & \text { : Citra merek } \\ \mathrm{E} & \text { : Erorr }\end{array}$

\section{HASIL DAN PEMBAHASAN}

Analisis Regresi Berganda

Tabel 2

Hasil Analisis Regresi Linear Berganda

\begin{tabular}{|c|c|c|c|c|c|}
\hline \multicolumn{6}{|c|}{ Dependen Variabel Y = Loyalitas pelanggan } \\
\hline \multirow[t]{2}{*}{ Variabel Independen } & \multicolumn{2}{|c|}{$\begin{array}{l}\text { Unstandardized } \\
\text { Coefficients }\end{array}$} & \multirow{2}{*}{$\begin{array}{c}\text { Standardized } \\
\text { Coefficients } \\
\text { Beta }\end{array}$} & \multirow{2}{*}{$\mathbf{T}$} & \multirow{2}{*}{ Sig } \\
\hline & B & $\begin{array}{c}\text { Standar } \\
\text { Error }\end{array}$ & & & \\
\hline $\mathrm{C}=$ Costanta & 1.044 & .276 & & 3.786 & .000 \\
\hline Harga $\left(X_{1}\right)$ & .260 & .078 & .286 & 3.317 & .001 \\
\hline Citra merek $\left(\mathrm{X}_{2}\right)$ & .505 & .082 & .530 & 6.146 & .000 \\
\hline $\begin{array}{ll}\text { Multiple } \mathrm{R} & =.735^{\mathrm{a}} \\
\mathrm{R} \text { Square }\left(\mathrm{R}^{2}\right) & =0.540\end{array}$ & & & $\mathrm{~F}=.000$ & & \\
\hline
\end{tabular}

Hasil tersebut apabila ditulis dalam bentuk persamaan regresinya adalah sebagai berikut:

$Y=1.044+0.260 X_{1}+0.505 X_{2}$

\section{Pembahasan}

1. Nilai konstanta sebesar 1.044, artinya jika variabel independen (harga dan citra merek) bernilai 0 , maka variabel dependen (loyalitas pelanggan pada swalayan grand hero Kota Palu) nilainya sebesar 1.044 dengan total nilai $\mathrm{R}$ square keseluruhan $\left(\mathrm{R}^{2}\right)=0.540$.

2. Koefisien regresi variabel harga $\left(X_{1}\right)$ sebesar 0.260 , hal ini menunjukan bahwa apabila harga naik satu rupiah maka loyalitas pelanggan yang menggunakan produk kosmetik viva berbelanja pada swalyan grand hero Kota Palu akan meningkat sebesar 0.260 atau $26 \%$.

3. Koefesien regresi variabel citra merek $\left(\mathrm{X}_{2}\right)$ sebesar 0.505 , hal ini menunjukan bahwa apabila citra merek yang dimensinya kualitas/mutu, dapat dipercaya/di andalkan, manfaat atau fungsi dan citra yang dimiliki oleh merek itu sendiri pada swalayan grand hero di Kota Palu akan meningkat sebesar 0.505 atau $50.5 \%$.

4. Di lihat dari nilai Beta, variabel citra merek menggunakan produk kosmetik viva $\left(\mathrm{X}_{2}\right)$ yang berpengaruh dominan terhadap loyalitas pelanggan $(\mathrm{Y})$ adalah citra merek $\left(\mathrm{X}_{2}\right)$ karena dimensi tersebut memiliki nilai Beta terbesar yaitu, 0.505, sehingga dapat di simpulkan bahwa citra merek adalah variabel yang paling besar pengaruhnya terhadap loyalitas pelanggan yang menggunakan produk kosmetik viva di Kota Palu. 


\section{KESIMPULAN DAN SARAN}

\section{Kesimpulan}

1. Harga dan citra merek secara serempak berpengaruh signifikan terhadap loyalitas pelanggan pada swalayan grand hero di Kota Palu.

2. Harga yang secara parsial berpengaruh terhadap loyalitas pelanggan diswalayan grand hero di Kota Palu, dan indikator yang sangat berpengaruh dalam variabel harga ini adalah harga relatif terjangkau, harga bervariasi yang berpengaruh terhadap loyalitas pelanggan.

3. Citra merek secara parsial berpengaruh terhadap loyalitas pelanggan pada swalayan grand hero di Kota Palu. Variabel citra merek kualitas/mutu, dapat percaya/diandalkan, manfaat/fungsi merek dan citra yang dimiliki oleh merek. Keempat dimensi tersebut yang paling berpengaruh terhadap loyalitas pelanggan adalah kualitas/mutu yang memiliki indikator yaitu produk yang dihasilkan berkualitas bagus dan baik serta dicantumkan tanda kadaluarsa.

\section{Saran}

a) Peneliti menyarankan kepada swalayan grand hero khusunya pada penjualan viva kosmetik untuk selalu mempertahankan harga yang diberikan setiap tahunnya kepada para konsumen, guna untuk mempertahakan pelanggan yang ada agar bisa melakukan loyalitas berikutnya.

b) Mengingat citra merek telah terbukti paling berpengaruh terhadap loyalitas pelanggan, hendaknya PT. Vitapharm sebagai pemiliki produk Viva kosmetik pada swalayan grand hero selalu memperhatikan harga yang di tetapkannya agar dapat selalu diterima oleh setiap pelanggannya. Menetapkan harga yang sesuai dan memberikan diskon disetiap waktu tertentu sebaiknya tetap dilakukan oleh pihak manajemen untuk tetap menjaga loyalitas pelanggan.

c) Meskipun pengaruh harga tidak sebesar variabel citra merek, hendaknya pihak manajemen Viva kosmetik tetap harus memperhatikan harga yang telah dibangun oleh pihak manajemen ataupun yang dibentuk oleh pelanggan. Hendaknya memperhatikan keinginan pelanggan dan tetap melayani semua segmen serta memberikan desain produk yang profesional dan modern.

d) Hasil penelitian di ketahui bahwa pengaruh harga dan brand image terhadap loyalitas pelanggan mempunyai pengaruh yang positif. Untuk kedepannya, ada baiknya jika pihak perusahaan lebih meningkatkan harga dan brand image, misalnya dengan mengevaluasi ataupun memperbaharui kekurangan dari produk Viva kosmetik, sehingga konsumen menjadi senang dengan banyaknya varian dari viva kosmetik tersebut, dan loyalitas pelanggan pun akan meningkat.

f) Untuk melengkapi hasil penelitian, maka sebaiknya di lakukan penelitian serupa seperti kepuasan, kualitas terhadap loyalitas pelanggan dengan objek penelitian yang berbeda agar memperoleh kesimpulan yang lebih lengkap dan dapat dipertanggung jawabkan.

\section{REFERENSI}

Ekasari, Novita. (2014). Pengaruh promosi berbasis Social media terhadap keputusan pembelian produk jasa Pembiayaan kendaraan PT. BFI Finance Jambi. Jurnal Volume 16, Nomor 2, Hal. 81-102. (ISSN: 0852-8349). Universitas Jambi.

Foster, Bob. (2008). Manajemen Ritel. Bandung: Alfabeta.

Griffin, R. W. (2005). Metodologi Penelitian Bisnis: Salah Kaprah Dan Pengalaman- pengalaman. Jakarta: Erlangga.

Kotler, P, dan Keller, K, L. (2009). Manajemen Pemasaran. Edisi 13 Jilid 2. Terjemahan Bob Sabran MM. Jakarta: Erlangga.

Kotler, Philip \& Amstrong, Gary., (2008), Prinsip-prinsip Pemasaran. Edisi Keduabelas, Jilid 1 Jakarta: Erlangga.

Sangadji, M. dan Shopiah. (2013). Perilaku Konsumen Pendekatan Praktis Disertai: Himpunan Jurnal Penelitian. Yogyakarta: CV Andi Offset.

Schiffman, L.G dan L.L Kanuk. (2011). Consumer Behavior. $7^{\text {th }}$ Edition . New Jersey: Prentice Hall.

Sugiyono. (2014). Metode Penelitian Kuantitatif, Kualitatif, dan $R \& D$. Bandung: Alfabeta.

Sugiyono. (2013). Statistika Untuk Penelitian, Bandung: Alfabeta. 
Adawiah, R.

Sulistian, Ogi. (2011). Pengaruh Brand Image Terhadap Loyalitas Pelanggan Rokok Gudang Garam Filter. Jurnal Manajemen Bisnis. Universitas Kuningan.

Tjiptono, F., \& Chandra, G. (2012). Pemasaran Strategik. Yogyakarta: C.V Andi Offset.

Tjiptono, F. (2014). Pemasaran Jasa. Yogyakarta: C.V Andi Offset.

Vinci, Maharani. (2009). Manajemen Bisnis Eceran. Bandung: Sinar Baru Algensindo. 